2 Title: The effect of abiotic and biotic stress on the salicylic acid biosynthetic pathway

5 Bernal-Vicente Agustina ${ }^{1}$ (abernal@abiopep.com); Petri Cesar² (cesar.petri@upct.es);

6 Hernández José Antonio ${ }^{1}$ (jahernan@cebas.csic.es); Diaz-Vivancos Pedro ${ }^{{ }^{*}}$

7 (pdv@cebas.csic.es)

$10{ }^{1}$ Biotechnology of Fruit Trees Group, Dept. Plant Breeding, CEBAS-CSIC, Campus

11 Universitario de Espinardo, 25. 30100 Murcia (Spain)

$12{ }^{2}$ Departamento de Producción Vegetal, Universidad Politécnica de Cartagena, Paseo

13 Alfonso XIII, 48, 30203 Cartagena (Spain)

14

15

$16 *$ Corresponding author

17 Dr. Pedro Diaz-Vivancos (pdv@ cebas.csic.es)

18 CEBAS-CSIC, Campus Universitario de Espinardo, 25. 30100 Murcia (Spain)

19 Phone number: +34 968396200 ; FAX: +34 968396213

20

21

22

Date of submission: 17 October 2017

23

Number of tables: 2

24

Number of figures: 7

25

Word count: 4890

26

27

28

29

30

31 


\section{Title: The effect of abiotic and biotic stress on the salicylic acid biosynthetic pathway from mandelonitrile in peach}

\section{Running title: Salicylic acid biosynthesis from mandelonitrile under stress}

\section{Highlight:}

We show that the recently suggested third pathway for SA biosynthesis from mandelonitrile in peach is also functional under both abiotic and biotic stress conditions.

\section{Abstract}

Salicylic acid (SA) plays a central role in plant responses to environmental stresses via the SA-mediated regulation of many metabolic and molecular processes. In a recent study, we suggested a third pathway for SA biosynthesis from mandelonitrile (MD) in peach plants. This pathway is alternative to the phenylalanine ammonia-lyase pathway and links SA biosynthesis and cyanogenesis. In the present work, we show that this new SA biosynthetic pathway is also functional under abiotic (salt) and biotic (Plum pox virus infection) stress conditions, although the contribution of this pathway to the SA pool does not seem to be important under such conditions. Treating peach plants with MD not only affected the SA content, but it also had a pleiotropic effect on abscisic acid and jasmonic acid levels, two well-known stress related hormones, as well as on the $\mathrm{H}_{2} \mathrm{O}_{2}$-related antioxidant activities. Furthermore, MD improved plant performance under the stressful conditions, probably via the activation of different signaling pathways. We have thus proven that SA is not limited to biotic stress responses, but that it also plays a role in the response to abiotic stress in peach, although the physiological functions of this new SA biosynthetic pathway from MD remain to be elucidated.

Keywords: antioxidative metabolism; cyanogenesis; mandelonitrile; metabolomics; peach; Plum pox virus; salicylic acid; salt stress 


\section{Abbreviations}

ABA, abcisic acid; APX, ascorbate peroxidase; BA, benzoic acid; CAT, catalase; CNglcs, cyanogenic glycosides; MD, mandelonitrile; NPR1, non-expressor of pathogenesis-related gene; PAL, phenylalanine ammonia-lyase; Phe, phenylalanine; POX, peroxidase; PPV, Plum pox virus; SA, salicylic acid; SOD, superoxide dismutase; TRX, thioredoxins

\section{Introduction}

The role of phytohormones alleviating the adverse effects of both abiotic and biotic stresses in plants has been widely described in the literature. Among the plant hormones, salicylic acid (SA) acts as a signalling and regulatory molecule in plant responses to environmental stresses via the SA-mediated control of metabolic and molecular processes (Khan et al., 2015; Liu et al., 2015). In a previous work, we described a third pathway for SA biosynthesis from mandelonitrile (MD) in peach plants. In this pathway, MD acts as an intermediary molecule between cyanogenic glycoside turnover and SA biosynthesis (DiazVivancos et al., 2017). The contribution of the different biosynthetic pathways to the total SA content varies depending on the plant species, the physiological and developmental stage, and the environmental conditions (Catinot et al., 2008; Chen et al., 2009; Dempsey et al., 2011; Ogawa et al., 2006). For example, although it is generally accepted that the contribution of the phenylalanine (Phe) ammonia-lyase (PAL) pathway to the total SA pool is small, this pathway gains importance during plant-pathogen interactions (Liu et al., 2015). Moreover, treatment with $1 \mathrm{mM}$ MD has been found to increase SA content and provide partial protection against Plum pox virus (PPV) infection in peach plants (DiazVivancos et al. 2017).

Both biotic and abiotic environmental stresses lead to considerable yield drop, causing important economic losses. Among biotic stresses, Sharka, a common disease caused by PPV, is the most important viral disease affecting Prunus species. In previous studies, we have shown that PPV infection induces oxidative stress at the subcellular level in susceptible varieties (Diaz-Vivancos et al., 2006; Hernandez et al., 2006). On the other hand, salinity is one of the most significant abiotic challenges affecting plant productivity, 
particularly in arid and semi-arid climates (Acosta-Motos et al., 2017). In order to cope with stressful conditions, plants have to induce different physiological and biochemical mechanisms. One common consequence of exposure to environmental stress conditions is the establishment of oxidative signaling that triggers defense pathways (Foyer and Noctor, 2005). The defense signaling output occurs in conjunction with other plant signaling molecules, particularly SA. Moreover, other hormones such as jasmonic acid (JA) and abscisic acid (ABA) have been described as regulators/modulators of plant defense responses. The crosstalk between hormone pathways therefore determines plant responses to environmental stresses at multiple levels (Alazem and Lin, 2015).

Due to its role in diverse biological processes, SA has been proposed as a potential agronomic factor for improving the stress response in plants of agro-economic interest. Nevertheless, even though SA has been the focus of intensive research, the physiological, biochemical and molecular mechanisms underpinning SA-induced stress tolerance have not been fully characterized (Khan et al., 2015). The accumulation of SA in response to several stress conditions has been described, as has the induction of stress tolerance by the exogenous application of SA or analogues; nevertheless, the mechanisms by which SA biosynthesis is regulated by each stress are poorly understood (Miura and Tada, 2014).

In this work, we analyzed the effect of abiotic $(\mathrm{NaCl})$ and biotic (Plum pox virus infection) stresses on the SA biosynthesis from MD in micropropagated peach shoots and in peach seedlings. In addition, because it has been described that SA can induce redox stress via increased $\mathrm{H}_{2} \mathrm{O}_{2}$ content (Durner and Klessig, 1995; Rao et al., 1997), we also determined the activities of $\mathrm{H}_{2} \mathrm{O}_{2}$-scavenging [ascorbate peroxidase (APX), peroxidase (POX) and catalase (CAT)] and $\mathrm{H}_{2} \mathrm{O}_{2}$-producing [superoxide dismutase (SOD)] enzymes. Finally, we also analyzed the ABA and JA content, as well as the expression of two genes involved in redox signaling in peach seedlings. 
125

126

127

128

\section{Material and Methods}

\section{Plant material}

The assays were performed on micropropagated GF305 peach (Prunus persica L.) shoots and GF305 peach seedlings, which were submitted to mild $\mathrm{NaCl}$ stress and PPVinfection, either in the presence or absence of MD and Phe (MD precursor) treatments.

In the micropropagated shoots, abiotic salt stress was imposed by adding $30 \mathrm{mM}$ $\mathrm{NaCl}$ to the micropropagation media, whereas PPV-infected peach shoots (ClementeMoreno et al., 2011) were used to assess the biotic stress conditions. Under in vitro conditions, all the assays were performed in the presence or absence of $200 \mu \mathrm{M}\left[{ }^{13} \mathrm{C}\right] \mathrm{MD}$ or $\left[{ }^{13} \mathrm{C}\right]$ Phe (Campro Scientific GmbH, Germany), as described in Diaz-Vivancos et al. (2017).

Under greenhouse conditions, GF305 peach seedlings grown in 2 L pots were first submitted to an artificial rest period (eight weeks) in a cold chamber to ensure uniformity and fast growth. The salt-stressed seedlings were then irrigated once a week with $34 \mathrm{mM}$ $\mathrm{NaCl}$ in the presence or absence of $1 \mathrm{mM}$ MD or Phe (Diaz-Vivancos et al. 2017) for seven weeks. The PPV-infected peach seedlings (Hernández et al., 2004) were treated with $1 \mathrm{mM}$ MD or Phe for six weeks and then submitted to an artificial rest period again, which was necessary to ensure the later multiplication of the virus. Then, six weeks after the second artificial rest period, the seedlings were inspected for sharka symptoms and were irrigated with either $1 \mathrm{mM}$ MD or Phe during these six weeks. For all the conditions, 12 seedlings were assayed, and another 12 plants were kept as control.

\section{Metabolomic analysis}

The levels of Phe, MD, amygdalin, benzoic acid and SA were determined in in vitro micropropagated shoots using an Agilent 1290 Infinity UPLC system coupled to a 6550 Accurate-Mass quadrupole TOF mass spectrometer (Agilent Technologies) at the Metabolomics Platform at CEBAS-CSIC (Murcia, Spain), as previously described (DiazVivancos et al. 2017). The hormone levels (ABA, JA and SA) in the leaves of non-stressed and stressed GF305 seedlings treated with MD or Phe were determined using a UHPLCmass spectrometer (Q-Exactive, ThermoFisher Scientific) at the Plant Hormone Quantification Platform at IBMCP (Valencia, Spain). 
155

156

157

158

159

160

161

162

163

164

165

166

167

168

169

170

171

172

173

174

175

176

177

178

179

180

181

182

\section{Enzymatic antioxidant determination}

The APX, POX, CAT and SOD activities were assayed as previously described (Diaz-Vivancos et al., 2008; Diaz-Vivancos et al., 2013; Diaz-Vivancos et al., 2006) in extracts obtained from in vitro shoots and ex vitro leaf samples following the extraction method described in Diaz-Vivancos et al. (2017). Protein determination was performed according to the method of Bradford (Bradford, 1976).

\section{Gene expression}

RNA samples from peach seedling leaves were extracted using a GF1-Total RNA Extraction Kit (Vivantis) according to the manufacturer's instructions. The expression levels of the redox-regulated genes NPR1 (Non-Expressor of Pathogenesis-Related Gene 1) and $\operatorname{Tr} x H$ (thioredoxin $H$ ), as well as the reference gene translation elongation factor II (TEF2) (Tong et al., 2009), were determined by real-time RT-PCR using the GeneAmp 7500 sequence detection system (Applied Biosystems, Foster City, CA, USA) (Faize et al., 2013). The accessions and primer sequences were as follows: NPRl (DQ149935; forward 5'-tgcacgagctcctttagtca-'3; $\quad$ reverse $5^{\prime}$-cggcttactgcgatcctaag-'3); $\operatorname{Tr} x H \quad$ (AF323593.1; forward 5'-tggcggagttggctaagaag-'3; 5'-ttcttggcacccacaacctt-'3); and TEF2 (TC3544; forward 5'-ggtgtgacgatgaagagtgatg-'3; reverse 5'-gaaggagagggaaggtgaaag-'3). Relative quantification of gene expression was calculated by the Delta-Delta $\mathrm{Ct}$ method, and the expressions of the genes of interest were normalized with the endogenous control TEF2.

\section{Statistical analysis}

The data were analyzed by one-way or two-way ANOVA using SPSS 22 software. Means were separated with Duncan's Multiple Range Test $(\mathrm{P}<0.05)$. 


\section{Results}

Effect of salt stress and PPV infection on cyanogenic glycoside turnover and SA biosynthesis

In a previous work, we observed that the cyanogenic glycosides (CNglcs) pathway can be involved in a new SA biosynthetic pathway in peach, with MD acting as an intermediary molecule between both pathways (Diaz-Vivancos et al., 2017). In the current study, micropropagated NaCl-treated and PPV-infected GF305 shoots were fed with $\left[{ }^{13} \mathrm{C}\right]$ Phe or with $\left[{ }^{13} \mathrm{C}\right] \mathrm{MD}$. Based in our previous results, the CNglcs pathway is fully functional under our experimental conditions (Diaz-Vivancos et al. 2017).

In the presence of $\mathrm{NaCl}$, the Phe content decreased in non-treated (control) and MDand Phe-treated micropropagated shoots (Fig. 1). Surprisingly, the MD content dropped in $\left[{ }^{13} \mathrm{C}\right] \mathrm{MD}$-fed shoots subjected to $\mathrm{NaCl}$ stress, whereas $\mathrm{MD}$ significantly increased in control and $\left[{ }^{13} \mathrm{C}\right]$ Phe-fed shoots in the presence of $\mathrm{NaCl}$. Salt stress did not have any discernable effect on amygdalin levels, although the level was lower than that observed in the absence of $\mathrm{NaCl}$ (Fig. 1). Salt stress induced significant benzoic acid (BA) and SA accumulation in control and $\left[{ }^{13} \mathrm{C}\right] \mathrm{Phe}$-fed shoots, but not in $\left[{ }^{13} \mathrm{C}\right] \mathrm{MD}$-treated shoots, which maintained SA levels under the stress conditions (Fig. 1).

In the biotic stress assay, control and PPV-infected micropropagated shoots were also fed with $\left[{ }^{13} \mathrm{C}\right] \mathrm{Phe}$ or $\left[{ }^{13} \mathrm{C}\right] \mathrm{MD}$. In PPV-infected shoots, there was a significant increase in amygdalin as well as a significant decrease in MD (Fig. 2). BA levels significantly increased in non-treated and Phe-treated shoots. As a result, the SA levels rose significantly in these plants, while MD-treated plants maintained their SA levels (Fig. 2), similar to saltstressed shoots (Fig. 1). The SA concentration was significantly higher in MD- than in Phetreated shoots, however, as occurred in healthy plants (Fig. 2).

We determined the percentage of $\left[{ }^{13} \mathrm{C}\right]$-labelled compounds from the total content of Phe, MD and SA in NaCl-stressed and PPV-infected micropropagated peach shoots treated with either $\left[{ }^{13} \mathrm{C}\right] \mathrm{Phe}$ or with $\left[{ }^{13} \mathrm{C}\right] \mathrm{MD}$ (Fig. 3). Due to the high sensitivity of the UPLC-Quadrupole-TOF-MS system used for metabolomics analysis, we detected basal levels (about $10 \%$ ) of $\left[{ }^{13} \mathrm{C}\right] \mathrm{Phe},\left[{ }^{13} \mathrm{C}\right] \mathrm{MD}$ and $\left[{ }^{13} \mathrm{C}\right] \mathrm{SA}$ in control shoots (Fig. 3; DiazVivancos et al. 2017), regardless of the presence of $\mathrm{NaCl}$ or PPV. 
In micropropagated shoots submitted to $\mathrm{NaCl}$ stress, nearly $15 \%$ of the total $\mathrm{SA}$ quantified appeared as $\left[{ }^{13} \mathrm{C}\right] \mathrm{SA}$ after the $\left[{ }^{13} \mathrm{C}\right] \mathrm{MD}$ treatment. Regarding the $\left[{ }^{13} \mathrm{C}\right] \mathrm{Phe}$ treatment, nearly $17 \%$ of Phe or MD was labelled with $\left[{ }^{13} \mathrm{C}\right]$, and the percentage of $\left[{ }^{13} \mathrm{C}\right] \mathrm{SA}$ was lower than $10 \%$ (Fig. 3). In PPV-infected shoots treated with $\left[{ }^{13} \mathrm{C}\right] \mathrm{MD}, 26 \%$ of the MD and $14 \%$ of the SA was $\left[{ }^{13} \mathrm{C}\right]$-labelled compounds (Fig. 3). However, when plants were fed with $\left[{ }^{13} \mathrm{C}\right] \mathrm{Phe}$, only $13 \%$ of the MD and less than $10 \%$ of the SA appeared as $\left[{ }^{13} \mathrm{C}\right] \mathrm{MD}$ and $\left[{ }^{13} \mathrm{C}\right] \mathrm{SA}$, respectively (Fig. 3). Taken together, our results support the hypothesis that MD can be metabolized to SA in peach plants under abiotic and biotic stress conditions.

We also fed peach seedlings grown in a greenhouse with either MD or Phe, under both salt stress and PPV infection conditions. It is important to note that the age of the seedlings used for the biotic stress assays was different than the age of seedlings used for the abiotic stress experiment. This difference is due to the fact that PPV-infected seedlings were subjected to an additional artificial rest period in order to ensure later virus multiplication (see details in the Plant material description). For this reason, the data obtained from control and treated (MD or Phe) plants in the absence of stress conditions could vary between batches.

The SA levels in peach seedlings were statistically higher in MD-treated plants than in Phe-treated plants when $\mathrm{NaCl}$ was absent (Fig. 4A), which agrees with the data observed in micropropagated shoots (Fig. 1). Salt stress strongly increased (3-fold) the SA content in the control seedlings. In the Phe-treated seedlings, $\mathrm{NaCl}$ produced a significant increase in SA, whereas salt stress conditions did not statistically affect the SA levels in MD-treated seedlings (Fig. 4A). In PPV-infected seedlings, a similar increase (about 1.5-fold) in total SA content was observed in control and MD- and Phe-treated plants due to the infection (Fig. 4B).

\section{Effect on $\mathrm{H}_{2} \mathrm{O}_{2}$-scavenging and -producing enzymes}

Researchers have established that increases in SA content lead to an accumulation of $\mathrm{H}_{2} \mathrm{O}_{2}$ (Durner and Klessig, 1995; Rao et al., 1997). In this study, the effect of MD- and Phe-treatments under stress conditions on $\mathrm{H}_{2} \mathrm{O}_{2}$-scavenging (APX, POX and CAT) and $\mathrm{H}_{2} \mathrm{O}_{2}$-producing (SOD) enzymes was analyzed in micropropagated shoots and seedlings. In 
the absence of stress, the MD treatment produced a rise in CAT and SOD activities in micropropagated shoots. Meanwhile, Phe increased all the analyzed antioxidant activities in a similar manner (Tables 1 and 2).

When submitted to salt stress, micropropagated shoots showed lower POX activity than unstressed shoots. Under salt stress conditions, MD-treated shoots displayed a strong increase in SOD activity, whereas Phe-treated shoots showed increases in both POX and SOD activities (Table 1).

In peach seedlings not submitted to salt stress, the MD treatment decreased all the $\mathrm{H}_{2} \mathrm{O}_{2}$-scavenging enzymes analyzed, whereas Phe produced a decrease in CAT activity and a rise in SOD activity (Table 1). In control plants, $\mathrm{NaCl}$ stress reduced APX and CAT activities. Under the stress conditions, the MD treatment increased APX, POX, CAT and SOD activities; the Phe treatment, on the other hand, reduced SOD activity when compared to non-stressed, treated seedlings (Table 1).

In micropropagated peach shoots, PPV infection produced an increase in POX and SOD activities (Table 2). In PPV-infected shoots, the MD treatment decreased CAT activity but increased SOD activity when compared with uninfected shoots. In contrast, the Phe-treatment reduced APX, POX and CAT activities in relation to non-infected plants (Table 2).

Regarding the PPV assay in peach seedlings, it is important to remember that the control plants used in this experiment were different from those used in the $\mathrm{NaCl}$ stress experiment. In non-infected plants, both treatments reduced SOD activity in a similar manner, whereas Phe-treated plants also showed a strong decrease in CAT activity (Table 2). In control seedlings, PPV infection produced a decrease in APX and CAT activity and an increase in POX activity (Table 2). In MD-treated plants, PPV infection reduced APX, POX, CAT and SOD activities. In contrast, Phe-treated plants showed a 2-fold increase in POX and CAT activities, as well as a dramatic increase in SOD activity, and these changes paralleled a significant decrease in APX activity (4.3-fold) (Table 2). 


\section{Plant performance under the experimental conditions}

As part of this study, we assessed the effect of salt stress and PPV infection, in the presence or absence of $\mathrm{MD}$ and Phe, on plant performance. A growth/development parameter (number of branches and buds per plant) was determined for $\mathrm{NaCl}$-stressed seedlings, whereas the presence of sharka symptoms in peach leaves (phenotypic PPV symptoms score, Diaz-Vivancos et al. 2017) was recorded in PPV-infected seedlings.

In the absence of $\mathrm{NaCl}$, MD-treated plants developed less branches and buds than control and Phe-treated plants (Fig. 5A), although other growth parameters such as height did not change (data not shown). In non-treated (control) plants, salt stress slightly reduced the number of branches and buds. A different effect was observed in MD- and Phe-treated plants. In MD-treated plants, $\mathrm{NaCl}$ did not affect the number of branches and buds, whereas the number significantly decreased in Phe-treated seedlings under salt stress (Figure 5A). The presence of sharka symptoms in peach leaves was scored for each plant according to a scale of 0 (no symptoms) to 5 (maximum symptom intensity) (Rubio et al., 2005). According to the mean intensity of symptoms in the peach leaves, MD- and Phe-treated seedlings showed a significant decrease in PPV-induced symptoms (Fig. 5B).

\section{Effect on other stress-related hormones: $A B A$ and $J A$}

We also analyzed the effect of MD and Phe treatments on ABA and JA levels in peach seedlings submitted to both stress conditions. In the absence of $\mathrm{NaCl}$ stress, the $\mathrm{ABA}$ content in leaves was similar in all treatments, whereas JA levels were statistically lower in MD- and Phe-treated seedlings than in control plants (Fig. 6A). When plants were submitted to $\mathrm{NaCl}$ stress, control and Phe-treated peach plants showed increased $\mathrm{ABA}$ and JA levels. In addition, under these stress conditions, MD- and Phe-treated plants had lower JA levels than control plants (Fig. 6A).

Regarding the non-infected plants used for the biotic stress experiments, the MD and Phe treatments had no effect on JA or SA levels (Figs. 6B and 4B, respectively). However, the MD treatment did produce a drop in ABA levels (Fig. 6B). The effect of PPV infection on these plant hormones was somewhat different from that observed in $\mathrm{NaCl}-$ stressed plants. PPV infection only produced an increase in ABA content in MD-treated 
301 plants, whereas JA levels strongly increased in both the MD and Phe treatments, although the changes were only statistically significant in Phe-treated plants (Fig 6B).

\section{Gene expression of redox-related genes}

We also studied the effect of MD and Phe treatments on the Non-Expressor of Pathogenesis-Related Gene $1(N P R l)$ and thioredoxin $\mathrm{H}(\operatorname{Tr} x H)$ expression levels in peach seedlings submitted to both stress conditions. NPRl is one of the best described redoxrelated genes, and its expression is modulated by SA. In addition, thioredoxins (Trx) are also involved in SA-induced NPRl conformational changes (Dong, 2004; Tada et al., 2008; Vieira Dos Santos and Rey, 2006).

The chemical treatments did not produce any significant changes in NPRI and TrxH expression in the absence of $\mathrm{NaCl}$, although we observed a slight increase in $\operatorname{Tr} x H$ expression in Phe-treated seedlings (Fig. 7A). In older plants (control plants used for the PPV-experiment), however, both treatments increased $\operatorname{Tr} x H$ gene expression, whereas no changes in NPRl expression were observed (Fig. 7B).

When salt stress was imposed, MD-treated plants displayed a significant increase in $\operatorname{Tr} x H$ expression in relation to controls and Phe-treated seedlings, whereas $\mathrm{NaCl}$ only affected the NPRl expression (decrease) in Phe-treated plantlets (Fig. 7A). On the other hand, PPV-infection had no effects on $\operatorname{Tr} x H$ expression, while the Phe treatment induced greater NPRl expression than that found in control plants (Fig 7B). 
330

331

332

333

334

335

336

337

338

339

340

341

342

343

344

345

346

347

348

349

350

351

352

353

354

355

356

357

358

359

360

stress and PPV infection as the abiotic and biotic stress conditions, respectively. Different authors have shown that $\mathrm{SA}$ can alleviate $\mathrm{NaCl}$-induced damage. However, this response is somewhat controversial, and the reported results depend on the plant species and growth conditions in addition to the SA concentration and application mode (Barba-Espin et al., 2011; Jayakannan et al., 2015; Khan et al., 2015). Regarding biotic stress, GF305 plants are commonly used for PPV-peach interaction studies, and it has been reported that PPV infection can induce oxidative stress at the subcellular level in these plants (Diaz-Vivancos et al., 2006).

We previously reported that at least $10 \%$ of the total SA content in micropropagated peach shoots could be due to CNglcs turnover via MD (Diaz-Vivancos et al., 2017). Under both stress conditions in the present study, MD treatment did not increase the total SA content (Figs. 1 and 2), although the presence of $\left[{ }^{13} \mathrm{C}\right] \mathrm{MD}$ did increase the level of $\left[{ }^{13} \mathrm{C}\right] \mathrm{SA}$ detected (near $15 \%$ of the detected SA was $\left[{ }^{13} \mathrm{C}\right]$-labelled; Fig. 3), indicating that the biosynthesis of SA from MD is still functional under stress conditions. Under salt stress conditions, the increase observed in SA in non-treated (control) and Phe-treated micropropagated peach shoots correlated with enhanced levels of the SA precursors MD and BA, whereas in PPV-infected shoots, this correlation only occurred in control shoots. Taken together, these results suggest that under stress conditions, the bulk of SA must come from isochorismate (IC) and PAL pathways (Dempsey et al., 2011). Accordingly, it has been suggested that the PAL pathway is the main route for SA biosynthesis in saltstressed rice seedlings (Sawada et al., 2006) and in tobacco mosaic virus (TMV)-infected Nicotiana tabacum plants (Yalpani et al., 1993). In addition, CNglcs is thought to play a possible role in unfavorable environmental conditions (Gleadow and Møller, 2014), so MD therefore potentially plays a role in plant defense responses.

When SA levels were analyzed in peach seedlings submitted to salt stress grown in a greenhouse, we observed a similar response to that observed under in vitro conditions. Furthermore, the SA content increased in both control and Phe-treated plants. $\mathrm{NaCl}$ stress also enhanced ABA and JA levels in the control and Phe-treated plants, but not in the MDtreated plants. In control seedlings, we observed an increased SA/JA ratio due to salinity, whereas in MD-treated seedlings, the SA/JA ratio slightly decreased. This response correlated with the fact that $\mathrm{NaCl}$ stress had no effect on the development of MD-treated 
361

362

363

364

365

366

367

368

369

370

371

372

373

374

375

376

377

378

379

380

381

382

383

384

385

386

387

388

389

390

391

seedlings. Accordingly, an increase in the SA/JA ratio has been proposed as a marker of saline stress (Acosta-Motos et al., 2016). ABA is a key modulator of the response to abiotic stress due to its important role in stomatal regulation. In addition, JA seems to act as a regulator of ABA biosynthesis (de Ollas and Dodd, 2016). Under saline conditions, we observed an increase in ABA levels in control and Phe-treated plants that correlated with a significant rise in JA. However, JA data should be considered with caution because JA seems to act very early in the response to stress (de Ollas and Dodd, 2016), whereas we analyzed its levels at the end of the $\mathrm{NaCl}$ stress period.

Regarding PPV-infected peach seedlings, severe symptoms were observed in nontreated plants, including venal chlorosis and leaf deformation. The mean intensity of PPV symptoms observed in non-treated plants, around 3.0 on a scale of 0 to 5 , confirmed the high susceptibility described for this cultivar (Hernández et al., 2004). Both MD and Phe treatments reduced the severity of symptoms, although Phe did so to a lesser extent than MD. This response correlated with higher levels of SA and JA in peach leaves, as well as with enhanced ABA levels in MD-treated seedlings. Accordingly, both SA and JA have been found to be necessary for systemic resistance to TMV in $N$. bentamiana plants (Zhu et al., 2014). These authors reported increased susceptibility to TMV in plants with impaired SA (no effect on JA levels) or JA (SA accumulation failure) pathways. On the other hand, $\mathrm{ABA}$ has been suggested to regulate plant defense responses in the early stages of pathogen infection via stomatal closure or the induction of callose deposition (Alazem and Lin, 2015). Although it is accepted that SA and ABA play antagonistic roles in plants, a simultaneous increase of ABA and SA due to Bamboo mosaic virus or Cucumber mosaic virus infection has also been reported (Alazem et al., 2014). Moreover, in the Arabidopsis mutant $v t c 1$ (ascorbic acid-deficient mutant), the induction of ABA and SA correlated with tolerance to two different types of pathogens (Barth et al., 2004).

In the present study, the correlation observed between SA levels and $\mathrm{H}_{2} \mathrm{O}_{2}$ content during environmental stress conditions could be explained by the "self-amplifying feedback loop" concept (Jayakannan et al., 2015), in which SA increases $\mathrm{H}_{2} \mathrm{O}_{2}$ levels and $\mathrm{H}_{2} \mathrm{O}_{2}$ induces SA accumulation (Dempsey and Klessig, 1995; Durner and Klessig, 1995; Rao et al., 1997). In MD-treated micropropagated peach shoots that were not subjected to stress, the increase in SA levels correlated with decreased APX and increased SOD activities. In 
the salinity assay, the accumulation of SA via MD in the non-NaCl-treated seedlings was associated with a decrease in $\mathrm{H}_{2} \mathrm{O}_{2}$-scavenging enzymes (APX, POX and CAT). In nonstressed peach seedlings, the accumulation of SA via MD in the salinity assay was associated with a decrease in $\mathrm{H}_{2} \mathrm{O}_{2}$-scavenging enzymes (APX, POX and CAT). However, this effect was not observed in older seedlings (those used as control plants in biotic stress experiments).

Under salinity, the MD treatment produced the best response in terms of stress tolerance under in vitro (Diaz-Vivancos et al., 2017) and ex vitro (Fig. 5A) conditions. A strong increase in SOD activity due to the combination of $\mathrm{MD}$ and $\mathrm{NaCl}$ was recorded in both growth conditions, favoring better control of the $\mathrm{O}_{2}{ }^{--}$generated under the salinity conditions. This response was accompanied by increases in APX and POX in peach seedlings, probably to overcome the $\mathrm{H}_{2} \mathrm{O}_{2}$ production by SOD. The modulation of antioxidant enzymes such as APX, POX and SOD in SA-mediated abiotic stress tolerance has been widely described in the literature (Khan et al., 2015). Some authors have attributed salt tolerance to higher constitutive levels of some antioxidant enzymes, whereas other authors have found that the coordinated up-regulation of the antioxidative enzymes activities seems to be one of the mechanisms involved in the salt-tolerance response (Acosta-Motos et al., 2017; Hernandez et al., 2001; Lopez-Gomez et al., 2007).

In PPV-infected micropropagated peach shoots, no correlation between $\mathrm{H}_{2} \mathrm{O}_{2-}$ related antioxidant activities and SA levels was found in control and Phe-treated shoots. Nevertheless, the PPV-infected shoots treated with MD displayed low CAT and high SOD activity. In PPV-infected peach seedlings, it was difficult to find any SA/antioxidant enzyme correlation. One of the most interesting results was the strong APX inhibition in Phe-treated plants. However, these plants had the highest level of SOD activity, and they also displayed the highest CAT and POX activity levels, as a compensatory mechanism to eliminate $\mathrm{H}_{2} \mathrm{O}_{2}$. Under our experimental conditions, both treatments (MD and Phe) reduced PPV symptoms in peach leaves thorough a mechanism that seems to be independent of antioxidative metabolism and reactive oxygen species production. This mechanism includes the interaction of SA with other plant hormones such as ABA and JA. It has been reported that the over-expression of SA biosynthesis genes as well as the exogenous application of SA or its analogues modulate different signaling pathways, enhancing plant responses to 
423 different viruses, including PPV (Alazem and Lin, 2015; Clemente-Moreno et al., 2010;

424 Clemente-Moreno et al., 2012).

425

426

427

428

429

430

431

432

433

434

435

436

437

438

439

440

441

442

443

444

445

446

447

448

449

450

451

452

453

NPR1 is a key regulator of the SA-mediated stress responses in plants. While the implication of NPR1 in plant-pathogen interactions is well known, its role during salt stress remains controversial, and induced a strong increase in SA content in control seedlings. In Phe-treated seedlings, the salt tolerance response in plants could be associated with both NPR1-independent and NPR1-dependent mechanisms (Jayakannan et al., 2015). In control and MD-treated peach seedlings submitted to salt stress, the NPRl gene expression did not change, even though $\mathrm{NaCl}$ however, $N P R l$ gene expression decreased. In a similar manner, in PPV-infected seedlings, only the Phe treatment affected the expression of NPRI. In agreement with these results, the expression of the NPRl gene was not altered in micropropagated peach shoots treated with benzothiadiazole (an SA analog) (ClementeMoreno et al., 2012). Other authors have suggested that the WHIRLY1 protein is able to perceive redox changes and is then translocated to the nucleus-triggering defense responses. This analogous mechanism to NPR1 could act as an NPR1-independent signaling pathway (Foyer et al., 2014). Nevertheless, NPR1 might be also regulated at the protein level, and the protein conformation may be sensitive to cellular redox changes (Dong, 2004). In this regards, the redox stress induced by salinity and/or PPV-infection could facilitate the release of NPR1 monomers and their entry into the nuclei (Durner and Klessig, 1995). Moreover, we have previously suggested that an oxidized environment due to MD treatment in the absence of stress could also modify the function of proteins such as NPR1 (Diaz-Vivancos et al., 2017).

Plant thioredoxins (Trx) play an essential role in protecting plants from oxidative damage. They can modulate antioxidant mechanisms regulating the redox status of target proteins as well as gene expression, including the expression of NPRI (Vieira Dos Santos and Rey, 2006). Trx-h3 and Trx-h5 can interact with NPR1 and reduce its oligomerization, an interaction that increases under SA treatments or pathogen infections (Tada et al., 2008). Under salt stress conditions, MD was the only treatment that induced $\operatorname{TrxH}$ gene expression. MD treatment also produced higher NPRl expression levels than Phe treatment, suggesting the role of TrxH in activating NPR1 monomerization as well as in enabling the activation of defense mechanisms to deal with the saline stress. However, in PPV-infected 
454 peach seedlings, no changes in $\operatorname{Tr} x H$ expression were observed in any treatment. In non-

455 infected peach plants, both MD and Phe treatments induced $\operatorname{Tr} x H$ gene expression and a 456 slight concomitant increase in NPRl expression (Diaz-Vivancos et al., 2017).

457 As a conclusion, based on our previous results suggesting that the CNgls pathway 458 can be involved in SA biosynthesis via MD, we have found evidence that this new SA 459 biosynthetic pathway also works also under stress conditions. The contribution of this 460 pathway to the SA pool does not seem to be relevant, however, under salt stress or PPV461 infection conditions. The physiological functions of this new SA biosynthetic pathway thus 462 remain to be elucidated in further studies. In addition, we have shown that the role of SA is 463 not limited to biotic stress responses, but that it also plays a role in the response to abiotic 464 stress in peach.

465

466

467

468

469

470

471

472

473

474

475

476

477

478

479

480

481

76

\section{Acknowledgments}

This work was supported by the Spanish Ministry of Economy and Competitiveness (Project AGL2014-52563-R). PDV and CP thank CSIC and UPCT, respectively, as well as the Spanish Ministry of Economy and Competitiveness for their 'Ramon \& Cajal' research contract, co-financed by FEDER funds. 


\section{References}

Acosta-Motos J, Ortuño M, Bernal-Vicente A, Diaz-Vivancos $P$, Sanchez-Blanco $M$, Hernandez J. 2017. Plant Responses to Salt Stress: Adaptive Mechanisms. Agronomy 7, 18.

Acosta-Motos JR, Ortuño MF, Álvarez S, López-Climent MF, Gómez-Cadenas A, Sánchez-Blanco MJ. 2016. Changes in growth, physiological parameters and the hormonal status of Myrtus communis L. plants irrigated with water with different chemical compositions. Journal of Plant Physiology 191, 12-21.

Alazem M, Lin K-Y, Lin N-S. 2014. The Abscisic Acid Pathway Has Multifaceted Effects on the Accumulation of Bamboo mosaic virus. Molecular Plant-Microbe Interactions 27, 177-189.

Alazem M, Lin N-S. 2015. Roles of plant hormones in the regulation of host-virus interactions. Molecular Plant Pathology 16, 529-540.

Barba-Espin G, Clemente-Moreno MJ, Alvarez S, Garcia-Legaz MF, Hernandez JA, Diaz-Vivancos P. 2011. Salicylic acid negatively affects the response to salt stress in pea plants. Plant Biology 13, 909-917.

Barth C, Moeder W, Klessig DF, Conklin PL. 2004. The Timing of Senescence and Response to Pathogens Is Altered in the Ascorbate-Deficient Arabidopsis Mutant vitamin c-1. Plant Physiology 134, 1784-1792.

Bradford MM. 1976. A rapid and sensitive method for the quantitation of microgram quantities of protein utilizing the principle of protein-dye binding. Analytical Biochemistry 72, 248-254.

Catinot J, Buchala A, Abou-Mansour E, Metraux JP. 2008. Salicylic acid production in response to biotic and abiotic stress depends on isochorismate in Nicotiana benthamiana. FEBS Letters $\mathbf{5 8 2}$, 473-478.

Clemente-Moreno MJ, Diaz-Vivancos P, Barba-Espin G, Hernandez JA. 2010. Benzothiadiazole and I-2-oxothiazolidine-4-carboxylic acid reduce the severity of Sharka symptoms in pea leaves: effect on antioxidative metabolism at the subcellular level. Plant Biology 12, 88-97.

Clemente-Moreno MJ, Diaz-Vivancos P, Piqueras A, Antonio Hernandez J. 2012. Plant growth stimulation in Prunus species plantlets by BTH or OTC treatments under in vitro conditions. Journal of Plant Physiology 169, 1074-1083.

Clemente-Moreno MJ, Piqueras A, Hernández JA. 2011. Implication of peroxidase activity in development of healthy and PPV-infected micropropagated GF305 peach plants. Plant Growth Regulation 65, 359-367.

Chen Z, Zheng Z, Huang J, Lai Z, Fan B. 2009. Biosynthesis of salicylic acid in plants. Plant Signaling \& Behavior 4, 493-496.

de Ollas C, Dodd IC. 2016. Physiological impacts of ABA-JA interactions under water-limitation. Plant Molecular Biology 91, 641-650. 
Decroocq V, Foulongne M, Lambert P, Gall OL, Mantin C, Pascal T, Schurdi-Levraud V, Kervella J. 2005. Analogues of virus resistance genes map to QTLs for resistance to sharka disease in Prunus davidiana. Molecular Genetics and Genomics 272, 680-689.

Dempsey DA, Klessig DF. 1995. Signals in plant disease resistance. Bulletin de l'Institut Pasteur 93, 167-186.

Dempsey DMA, Vlot AC, Wildermuth MC, Klessig DF. 2011. Salicylic Acid Biosynthesis and Metabolism. The Arabidopsis Book, e0156.

Diaz-Vivancos P, Bernal-Vicente A, Cantabella D, Petri C, Hernández JA. 2017. Metabolomic and Biochemical Approaches Link Salicylic Acid Biosynthesis to Cyanogenesis in Peach Plants. Plant and Cell Physiology doi: 10.1093/pcp/pcx135

Diaz-Vivancos P, Clemente-Moreno MJ, Rubio M, Olmos E, Garcia JA, Martinez-Gomez P, Hernandez JA. 2008. Alteration in the chloroplastic metabolism leads to ROS accumulation in pea plants in response to plum pox virus. Journal of Experimental Botany 59, 2147-2160.

Diaz-Vivancos P, Faize M, Barba-Espin G, Faize L, Petri C, Hernández JA, Burgos L. 2013. Ectopic expression of cytosolic superoxide dismutase and ascorbate peroxidase leads to salt stress tolerance in transgenic plums. Plant Biotechnology Journal 11 976-985.

Diaz-Vivancos P, Rubio M, Mesonero V, Periago PM, Barcelo AR, Martinez-Gomez P, Hernandez JA. 2006. The apoplastic antioxidant system in Prunus: response to long-term plum pox virus infection. Journal of Experimental Botany 57, 3813-3824.

Dong X. 2004. NPR1, all things considered. Current Opinion in Plant Biology 7, 547-552.

Durner J, Klessig DF. 1995. Inhibition of ascorbate peroxidase by salicylic acid and 2,6dichloroisonicotinic acid, two inducers of plant defense responses. Proceedings of the National Academy of Sciences of the United States of America 92, 11312-11316.

Faize M, Faize L, Petri C, Barba-Espin G, Diaz-Vivancos P, Clemente-Moreno MJ, Koussa T, Rifai LA, Burgos L, Hernandez JA. 2013. Cu/Zn superoxide dismutase and ascorbate peroxidase enhance in vitro shoot multiplication in transgenic plum. Journal of Plant Physiology 170, 625632.

Foyer CH, Karpinska B, Krupinska K. 2014. The functions of WHIRLY1 and REDOX-RESPONSIVE TRANSCRIPTION FACTOR 1 in cross tolerance responses in plants: a hypothesis. Philosophical Transactions of the Royal Society B: Biological Sciences 369.

Foyer CH, Noctor G. 2005. Redox homeostasis and antioxidant signaling: a metabolic interface between stress perception and physiological responses. Plant Cell 17, 1866-1875.

Gleadow RM, Møller BL. 2014. Cyanogenic Glycosides: Synthesis, Physiology, and Phenotypic Plasticity. Annual Review of Plant Biology 65, 155-185.

Hernandez JA, Diaz-Vivancos P, Rubio M, Olmos E, Ros-Barcelo A, Martinez-Gomez P. 2006. Long-term plum pox virus infection produces an oxidative stress in a susceptible apricot, Prunus armeniaca, cultivar but not in a resistant cultivar. Physiologia Plantarum 126, 140-152. 
Hernandez JA, Ferrer MA, Jimenez A, Barcelo AR, Sevilla F. 2001. Antioxidant systems and O(2)(.)$/ \mathrm{H}(2) \mathrm{O}(2)$ production in the apoplast of pea leaves. Its relation with salt-induced necrotic lesions in minor veins. Plant Physiol 127, 817-831.

Hernández JA, Rubio M, Olmos E, Ros-Barceló A, Martínez-Gómez P. 2004. Oxidative stress induced by long-term plum pox virus infection in peach (Prunus persica). Physiologia Plantarum 122, 486-495.

Jayakannan M, Bose J, Babourina O, Rengel Z, Shabala S. 2015. Salicylic acid in plant salinity stress signalling and tolerance. Plant Growth Regulation 76, 25-40.

Khan MI, Fatma M, Per TS, Anjum NA, Khan NA. 2015. Salicylic acid-induced abiotic stress tolerance and underlying mechanisms in plants. Frontiers in Plant Science 6, 462.

Liu X, Rockett KS, Kørner CJ, Pajerowska-Mukhtar KM. 2015. Salicylic acid signalling: new insights and prospects at a quarter-century milestone. Essays In Biochemistry 58, 101-113.

Lopez-Gomez E, San Juan MA, Diaz-Vivancos P, Beneyto JM, Garcia-Legaz MF, Hernandez JA. 2007. Effect of rootstocks grafting and boron on the antioxidant systems and salinity tolerance of loquat plants (Eriobotrya japonica Lindl.). Environmental and Experimental Botany 60, 151158.

Miura K, Tada Y. 2014. Regulation of water, salinity, and cold stress responses by salicylic acid. Frontiers in Plant Science 5, 4.

Ogawa D, Nakajima N, Seo S, Mitsuhara I, Kamada H, Ohashi Y. 2006. The phenylalanine pathway is the main route of salicylic acid biosynthesis in Tobacco mosaic virus-infected tobacco leaves. Plant Biotechnology 23, 395-398.

Rao MV, Paliyath G, Ormrod DP, Murr DP, Watkins CB. 1997. Influence of salicylic acid on H2O2 production, oxidative stress, and H2O2-metabolizing enzymes. Salicylic acid-mediated oxidative damage requires H2O2. Plant Physiology 115, 137-149.

Rivas-San Vicente M, Plasencia J. 2011. Salicylic acid beyond defence: its role in plant growth and development. Journal of Experimental Botany 62, 3321-3338.

Rubio M, Martínez-Gómez P, Pinochet J, Dicenta F. 2005. Evaluation of resistance to sharka (Plum pox virus) of several Prunus rootstocks. Plant Breeding 124, 67-70.

Sawada H, Shim I-S, Usui K. 2006. Induction of benzoic acid 2-hydroxylase and salicylic acid biosynthesis-Modulation by salt stress in rice seedlings. Plant Science 171, 263-270.

Tada Y, Spoel SH, Pajerowska-Mukhtar K, Mou Z, Song J, Wang C, Zuo J, Dong X. 2008. Plant Immunity Requires Conformational Charges of NPR1 via S-Nitrosylation and Thioredoxins. Science 321, 952-956.

Tong Z, Gao Z, Wang F, Zhou J, Zhang Z. 2009. Selection of reliable reference genes for gene expression studies in peach using real-time PCR. BMC Molecular Biology 10, 71. 
589

590

591

592

593

594

595

596

597

598

599

600

601

602

603

604

605

606

607

608

609

610

611

612

613

614

615

616

617

618

619

09

10

14

15

17

19

Vieira Dos Santos C, Rey P. 2006. Plant thioredoxins are key actors in the oxidative stress response. Trends in Plant Science 11, 329-334.

Yalpani N, Leon J, Lawton MA, Raskin I. 1993. Pathway of Salicylic Acid Biosynthesis in Healthy and Virus-Inoculated Tobacco. Plant Physiology 103, 315-321.

Zhu F, Xi DH, Yuan S, Xu F, Zhang DW, Lin HH. 2014. Salicylic acid and jasmonic acid are essential for systemic resistance against tobacco mosaic virus in Nicotiana benthamiana. Molecular Plant Microbe Interaction 27, 567-577.

6

7

8

99

0

01

603

4

05

06

7

11

2

13


620

621

622

623

624

625

Tables

Table 1. Effect of salt stress on APX, POX, CAT, and SOD activities on control and MDand Phe-treated GF305 peach in vitro shoots and seedlings. APX is expressed as nmol min ${ }^{1} \mathrm{mg}^{-1}$ protein. POX and CAT are expressed as $\mu \mathrm{mol} \mathrm{min}^{-1} \mathrm{mg}^{-1}$ protein. SOD as $\mathrm{U} \mathrm{mg}^{-1}$ protein. Data represent the mean $\pm \mathrm{SE}$ of at least four repetitions. Different letters in the same column indicate significant differences according to Duncan's test $(\mathrm{P} \leq 0.05)$.

\begin{tabular}{|c|c|c|c|c|c|}
\hline $\begin{array}{l}\text { In vitro } \\
\text { shoots }\end{array}$ & Treatment & APX & POX & CAT & SOD \\
\hline \multirow[t]{3}{*}{ - NaCl } & Control & $316.0 \pm 48.0 \mathrm{~b}$ & $1453.8 \pm 22.4 \mathrm{~cd}$ & $4.1 \pm 0.1 \mathrm{~b}$ & $36.2 \pm 2.5 \mathrm{~d}$ \\
\hline & MD & $257.0 \pm 32.7 \mathrm{~b}$ & $1600.4 \pm 231.0 \mathrm{bc}$ & $7.2 \pm 1.1 \mathrm{a}$ & $57.8 \pm 8.1 \mathrm{bc}$ \\
\hline & Phe & $490.9 \pm 35.9 \mathrm{a}$ & $1935.9 \pm 78.6 \mathrm{ab}$ & $6.5 \pm 0.4 \mathrm{a}$ & $56.0 \pm 3.4 \mathrm{bcd}$ \\
\hline \multirow[t]{3}{*}{$+\mathrm{NaCl}$} & Control & $253.9 \pm 26.1 \mathrm{~b}$ & $891.2 \pm 173.0 \mathrm{e}$ & $2.4 \pm 0.1 \mathrm{bc}$ & $40.6 \pm 8.3 \mathrm{~cd}$ \\
\hline & MD & $247.3 \pm 27.3 \mathrm{~b}$ & $1101.9 \pm 107.6 \mathrm{de}$ & $2.9 \pm 0.5 \mathrm{bc}$ & $81.7 \pm 9.1 \mathrm{a}$ \\
\hline & Phe & $448.6 \pm 42.9 \mathrm{a}$ & $2175.5 \pm 48.7 \mathrm{a}$ & $2.1 \pm 0.4 \mathrm{c}$ & $66.8 \pm 3.7 \mathrm{ab}$ \\
\hline Seedlings & Treatment & APX & POX & CAT & SOD \\
\hline \multirow[t]{3}{*}{ - NaCl } & Control & $344.9 \pm 64.6 \mathrm{a}$ & $1291.8 \pm 136.9 \mathrm{~b}$ & $96.1 \pm 6.8 \mathrm{a}$ & $119.1 \pm 17.1 \mathrm{~b}$ \\
\hline & MD & $198.2 \pm 15.7 \mathrm{~b}$ & $969.1 \pm 20.3 \mathrm{c}$ & $53.25 \pm 2.2 \mathrm{~d}$ & $107.9 \pm 4.9 \mathrm{~b}$ \\
\hline & Phe & $403.6 \pm 22.1 \mathrm{a}$ & $1323.7 \pm 53.0 \mathrm{ab}$ & $70.4 \pm 1.9 \mathrm{bc}$ & $198.3 \pm 12.9 \mathrm{a}$ \\
\hline \multirow[t]{3}{*}{$+\mathrm{NaCl}$} & Control & $213.84 \pm 33.0 \mathrm{~b}$ & $1378.7 \pm 167.6 \mathrm{ab}$ & $73.5 \pm 1.2 \mathrm{bc}$ & $127.2 \pm 14.8 \mathrm{~b}$ \\
\hline & MD & $371.9 \pm 13.8 \mathrm{a}$ & $1603.4 \pm 37.3 \mathrm{a}$ & $78.1 \pm 1.8 b$ & $230.5 \pm 5.1 \mathrm{a}$ \\
\hline & Phe & $356.1 \pm 34.8 \mathrm{a}$ & $1361.8 \pm 46.1 \mathrm{ab}$ & $66.5 \pm 0.8 \mathrm{c}$ & $139.0 \pm 21.0 \mathrm{~b}$ \\
\hline
\end{tabular}

626

627

628

629

630

631

632

633

634 


\begin{tabular}{cccccc}
\hline $\begin{array}{c}\text { In vitro } \\
\text { shoots }\end{array}$ & Treatment & APX & POX & CAT & SOD \\
\hline - PPV & Control & $316.0 \pm 48.0 \mathrm{~b}$ & $1453.8 \pm 22.4 \mathrm{c}$ & $4.1 \pm 0.1 \mathrm{~b}$ & $36.2 \pm 2.5 \mathrm{c}$ \\
& MD & $257.0 \pm 32.7 \mathrm{~b}$ & $\begin{array}{c}1600.4 \pm 231.0 \mathrm{bc} \\
7.2 \pm 1.1 \mathrm{a}\end{array}$ & $57.8 \pm 8.1 \mathrm{bc}$ \\
& Phe & $490.9 \pm 35.9 \mathrm{a}$ & $1935.9 \pm 78.6 \mathrm{ab}$ & $6.5 \pm 0.4 \mathrm{a}$ & $56.0 \pm 3.4 \mathrm{bcd}$ \\
+ PPV & Control & $312.7 \pm 22.6 \mathrm{~b}$ & $2133.4 \pm 138.1 \mathrm{a}$ & $3.6 \pm 0.3 \mathrm{~b}$ & $67.3 \pm 4.3 \mathrm{ab}$ \\
& MD & $373.9 \pm 41.3 \mathrm{~b}$ & $1890.9 \pm 177.2 \mathrm{ab}$ & $2.7 \pm 0.1 \mathrm{~b}$ & $80.8 \pm 11.9 \mathrm{a}$ \\
& Phe & $323.9 \pm 28.8 \mathrm{~b}$ & $1028.8 \pm 43.1 \mathrm{~d}$ & $4.1 \pm 0.4 \mathrm{~b}$ & $35.9 \pm 1.9 \mathrm{c}$ \\
\hline Seedlings & Treatment & $\mathbf{A P X}$ & $\mathbf{P O X}$ & $\mathbf{C A T}$ & SOD \\
\hline - PPV & Control & $965.2 \pm 30.6 \mathrm{a}$ & $776.5 \pm 56.4 \mathrm{~cd}$ & $22.8 \pm 0.5 \mathrm{a}$ & $556.5 \pm 11.9 \mathrm{~b}$ \\
& MD & $1052.1 \pm 77.2 \mathrm{a}$ & $959.7 \pm 42.9 \mathrm{c}$ & $24.7 \pm 0.3 \mathrm{a}$ & $257.8 \pm 19.5 \mathrm{c}$ \\
& Phe & $1009.3 \pm 45.5 \mathrm{a}$ & $776.7 \pm 35.4 \mathrm{~cd}$ & $9.8 \pm 0.3 \mathrm{~d}$ & $257.8 \pm 22.8 \mathrm{c}$ \\
+ PPV & Control & $937.8 \pm 32.9 \mathrm{~b}$ & $1158.2 \pm 105.8 \mathrm{~b}$ & $12.7 \pm 1.5 \mathrm{~cd}$ & $480.0 \pm 45.5 \mathrm{~b}$ \\
& MD & $823.3 \pm 12.4 \mathrm{~b}$ & $622.4 \pm 4.4 \mathrm{~d}$ & $16.8 \pm 1.4 \mathrm{bc}$ & $133.0 \pm 22.1 \mathrm{~d}$ \\
& Phe & $235.1 \pm 14.4 \mathrm{c}$ & $1616.6 \pm 60.9 \mathrm{a}$ & $20.5 \pm 1.8 \mathrm{ab}$ & $1125.8 \pm 57.9 \mathrm{a}$ \\
\hline
\end{tabular}

Table 2. Effect of PPV infection on APX, POX, CAT, and SOD activities on control and MD- and Phe-treated GF305 peach in vitro shoots and seedlings. APX is expressed as nmol

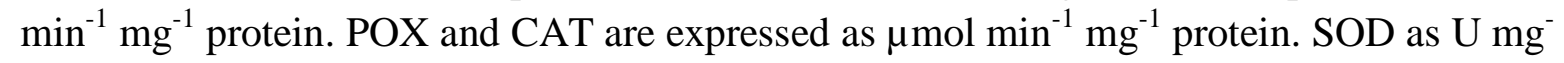
${ }^{1}$ protein. Data represent the mean $\pm \mathrm{SE}$ of at least four repetitions. Different letters in the same column indicate significant differences according to Duncan's test $(\mathrm{P} \leq 0.05)$.

641

642

643

644

645

646

647

648

649 
650

651

652

653

654

655

656

657

658

659

660

661

662

663

664

665

666

667

668

669

670

671

672

673

674

675

676

677

\section{Figure legends.}

Figure 1. Salicylic acid (SA) biosynthetic and cyanogenic glucosides (CNglcs) pathways in salt-stressed peach shoots micropropagated in the presence or absence of $\left[{ }^{13} \mathrm{C}\right] \mathrm{MD}$ or $\left[{ }^{13} \mathrm{C}\right]$ Phe. Total levels $\left(\mu \mathrm{M} \mathrm{g} \mathrm{g}^{-1} \mathrm{FW}\right)$ of amygdalin, benzoic acid, mandelonitrile, phenylalanine and SA are shown. Data represent the mean \pm SE of at least 12 repetitions of each treatment. Different letters indicate significant differences in each graph according to Duncan's test $(\mathrm{P} \leq 0.05)$. Blue arrows indicate the previously described SA biosynthesis in plants (dot arrow, putative), whereas red arrows show the new pathway suggested for peach plants.

Figure 2. Salicylic acid (SA) biosynthetic and cyanogenic glucosides (CNglcs) pathways in PPV-infected peach shoots micropropagated in the presence or absence of $\left[{ }^{13} \mathrm{C}\right] \mathrm{MD}$ or $\left[{ }^{13} \mathrm{C}\right]$ Phe. Total levels $\left(\mu \mathrm{M} \mathrm{g}{ }^{-1} \mathrm{FW}\right)$ of amygdalin, benzoic acid, mandelonitrile, phenylalanine and SA are shown. Data represent the mean \pm SE of at least 12 repetitions of each treatment. Different letters indicate significant differences in each graph according to Duncan's test $(\mathrm{P} \leq 0.05)$. Blue arrows indicate the previously described SA biosynthesis in plants (dot arrow, putative), whereas red arrows show the new pathway suggested for peach plants.

Figure 3. Percentage (from the total amount detected) of $\left[{ }^{13} \mathrm{C}\right]-$ phenylalanine, mandelonitrile and salicylic acid in non-stressed, NaCl-stressed and PPV-infected peach shoots micropropagated in the presence or absence of $\left[{ }^{13} \mathrm{C}\right] \mathrm{MD}$ or $\left[{ }^{13} \mathrm{C}\right] \mathrm{Phe}$. Under control conditions, approximately $10 \%\left[{ }^{13} \mathrm{C}\right]$ - mandelonitrile, phenylalanine and salicylic acid were observed (Diaz-Vivancos et al. 2017). Data represent the mean of at least 15 repetitions of each treatment.

Figure 4. Total SA level (ng $\mathrm{g}^{-1} \mathrm{DW}$ ) in the leaves of peach seedlings grown in the presence or absence of $\mathrm{MD}$ or Phe submitted to $34 \mathrm{mM} \mathrm{NaCl}$ (A) or PPV infection (B). Data represent the mean \pm SE of at least five repetitions of each treatment. Different letters indicate significant differences according to Duncan's test $(\mathrm{P} \leq 0.05)$. 
678 Figure 5. Effect on plant performance. The effect of chemical treatments and salt stress on 679 peach seedlings was assessed by the determination of the number of branches and buds per 680 plant (A). In (B), the phenotypic scoring for evaluating the resistance/susceptibility to PPV 681 infection (Decroocq et al., 2005) and sharka symptoms in peach seedlings is shown. Data 682 represent the mean $\pm \mathrm{SE}$ of at least 10 repetitions. Different letters indicate significant 683 differences according to Duncan's test $(\mathrm{P} \leq 0.05)$.

684 Figure 6. Effect on the stress-related hormones ABA and JA. Total ABA and JA levels (ng $\left.685 \mathrm{~g}^{-1} \mathrm{DW}\right)$ in the leaves of peach seedlings grown in the presence or absence of MD or Phe 686 submitted to $34 \mathrm{mM} \mathrm{NaCl}$ (A) or PPV infection (B). Data represent the mean $\pm \mathrm{SE}$ of at 687 least 5 repetitions of each treatment. Different letters indicate significant differences 688 according to Duncan's test $(\mathrm{P} \leq 0.05)$.

Figure 7. Gene expression of $\operatorname{Tr} x H$ and NPRlin the leaves of peach seedlings grown in the 690 presence or absence of $\mathrm{MD}$ or Phe submitted to $34 \mathrm{mM} \mathrm{NaCl}$ (A) or PPV infection (B). Data represent the mean $\pm \mathrm{SE}$ of at least five repetitions of each treatment. Different letters 692 indicate significant differences in each graph according to Duncan's test $(\mathrm{P} \leq 0.05)$.

693

694

695

696

697

698

699

700

701

702

703

704 
Fig. 1
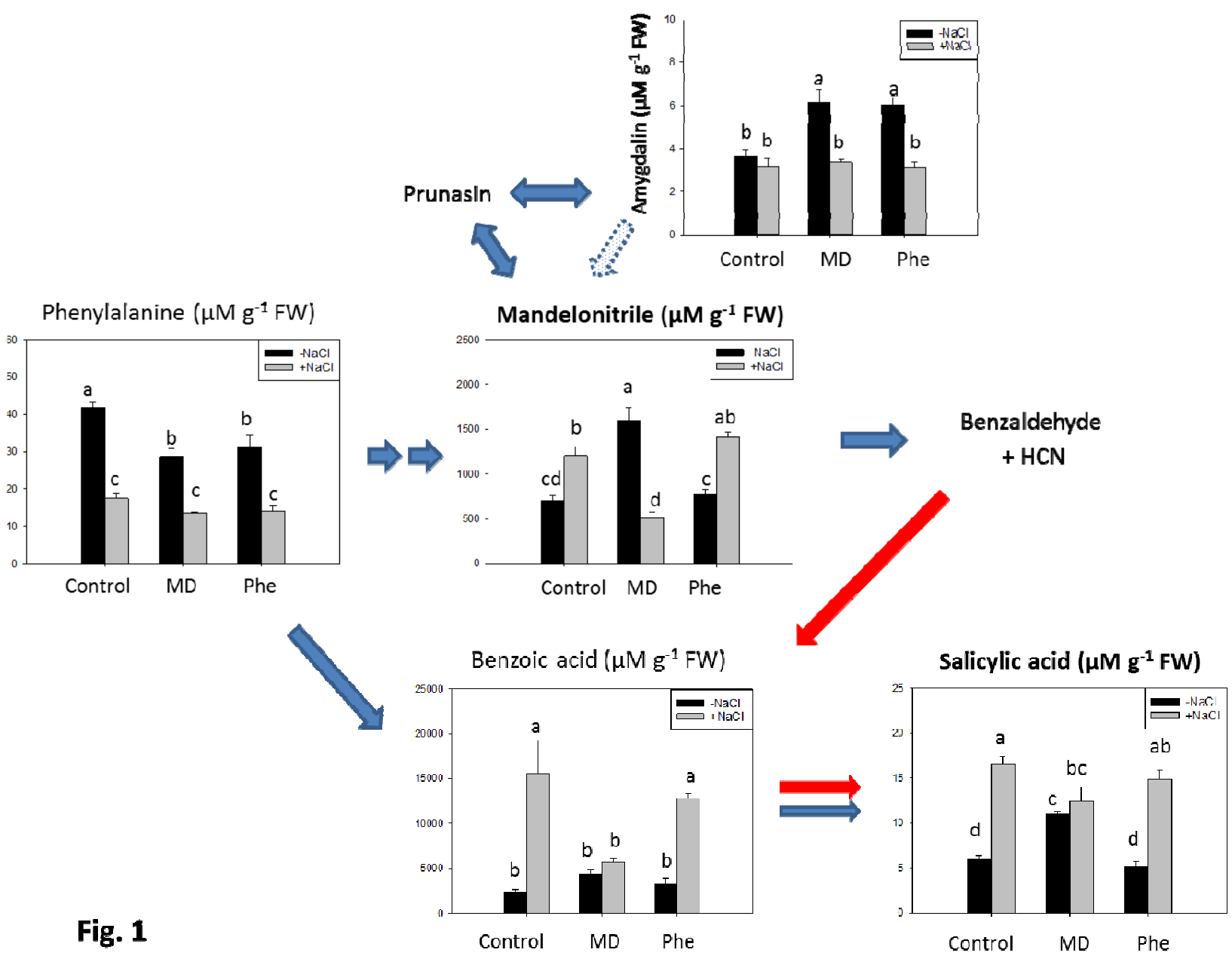

706 
Fig. 2
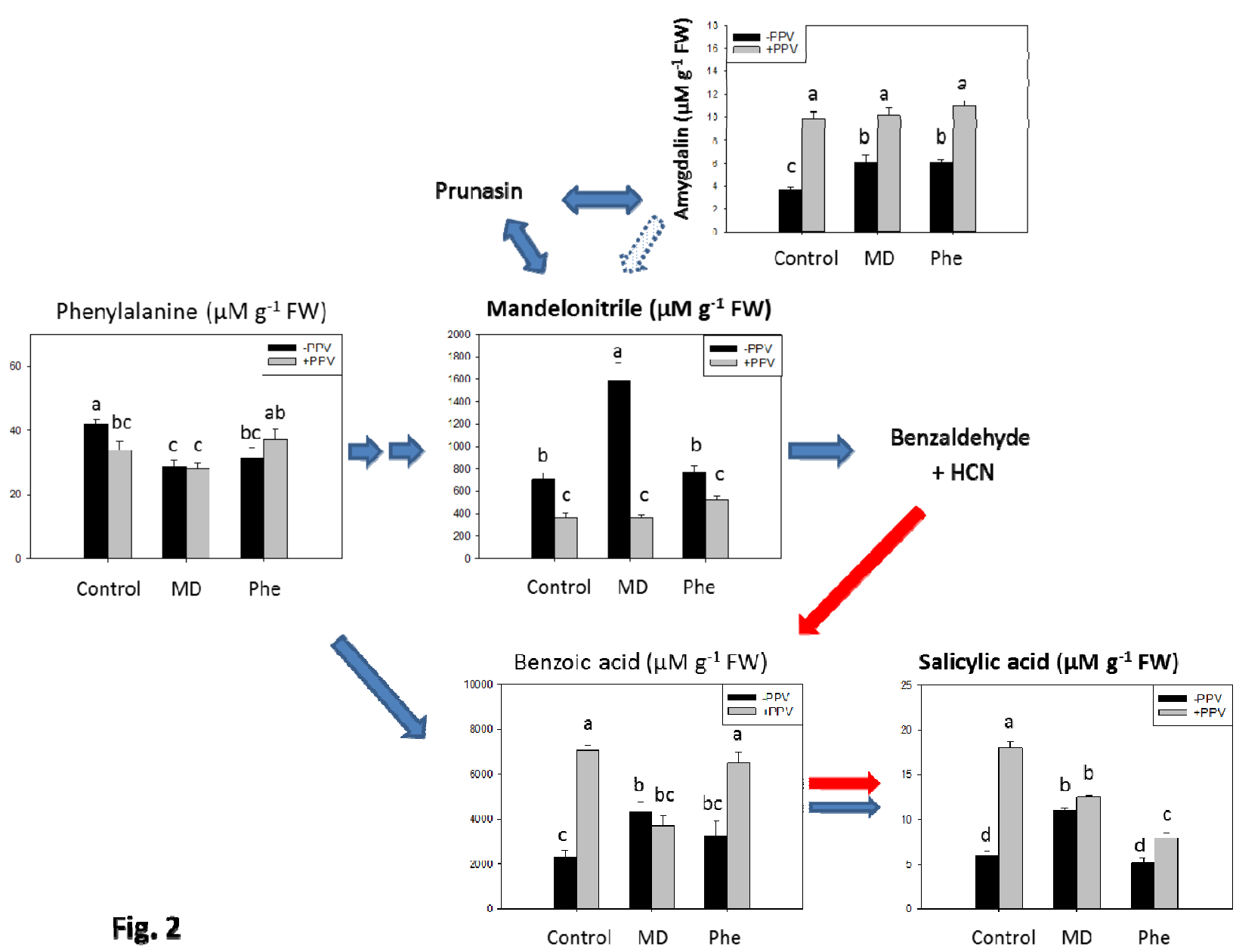
bioRxiv preprint doi: https://doi.org/10.1101/204636; this version posted October 17,2017 . The copyright holder for this preprint (which was not certified by peer review) is the author/funder. All rights reserved. No reuse allowed without permission.

727

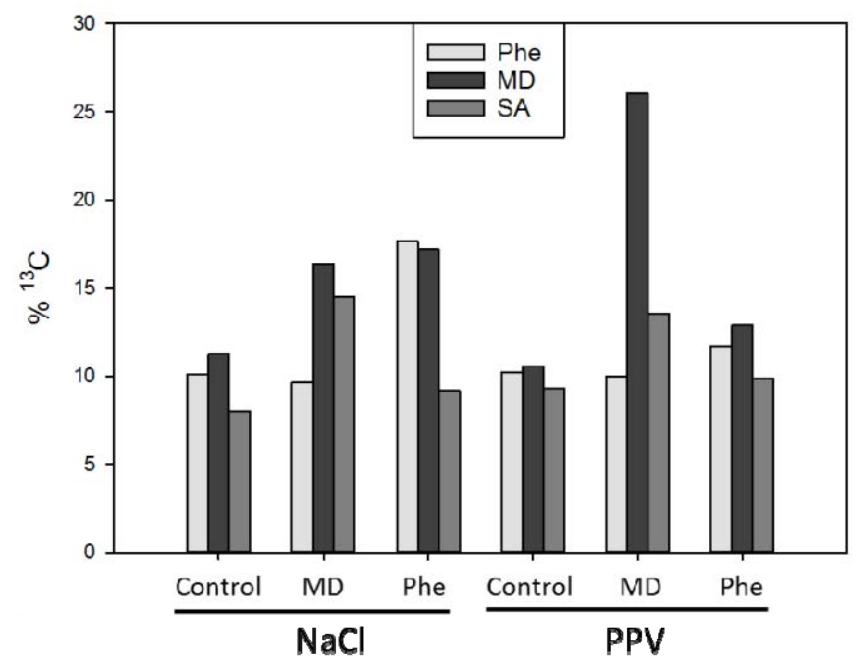

728

Fig. 3

729

730

731

732

733

734

735

736

737

738

739

740

741

742 
bioRxiv preprint doi: https://doi.org/10.1101/204636; this version posted October 17,2017 . The copyright holder for this preprint (which was not certified by peer review) is the author/funder. All rights reserved. No reuse allowed without permission.

743

A

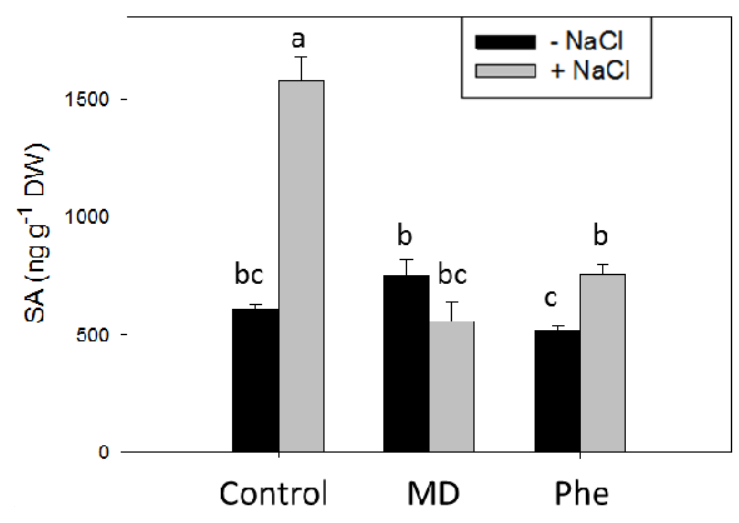

B

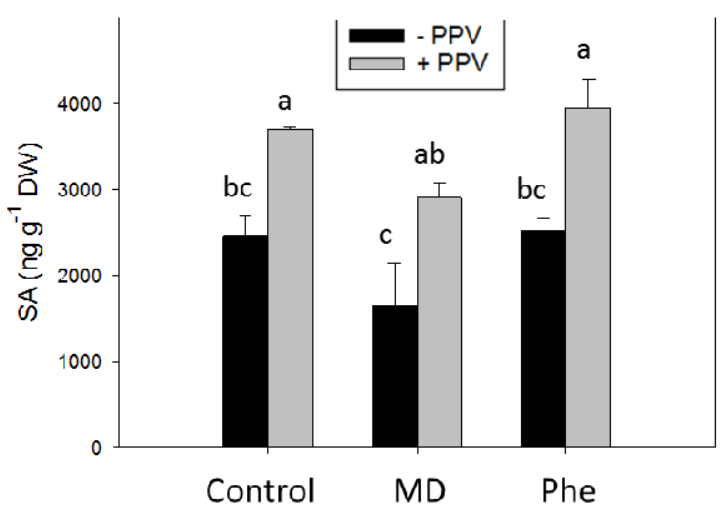

Fig. 4 
A

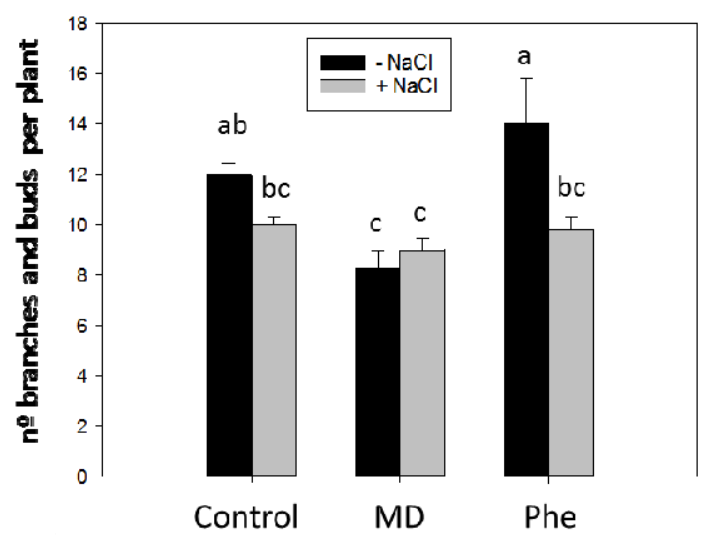

B

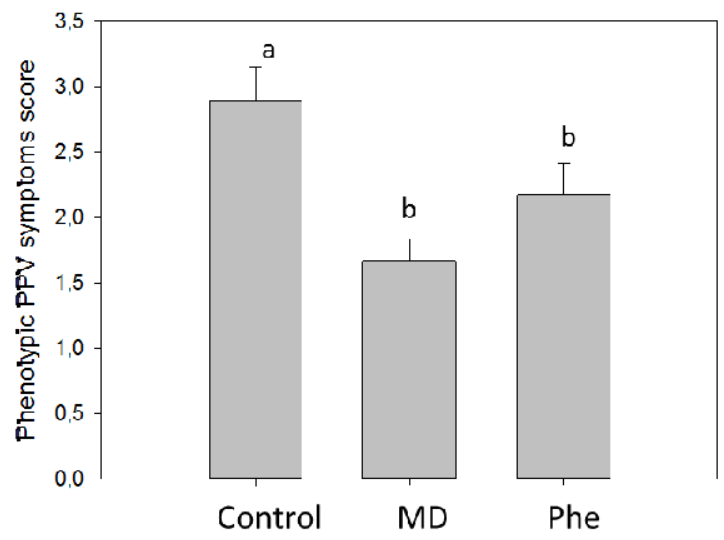

Flg. 5 
A

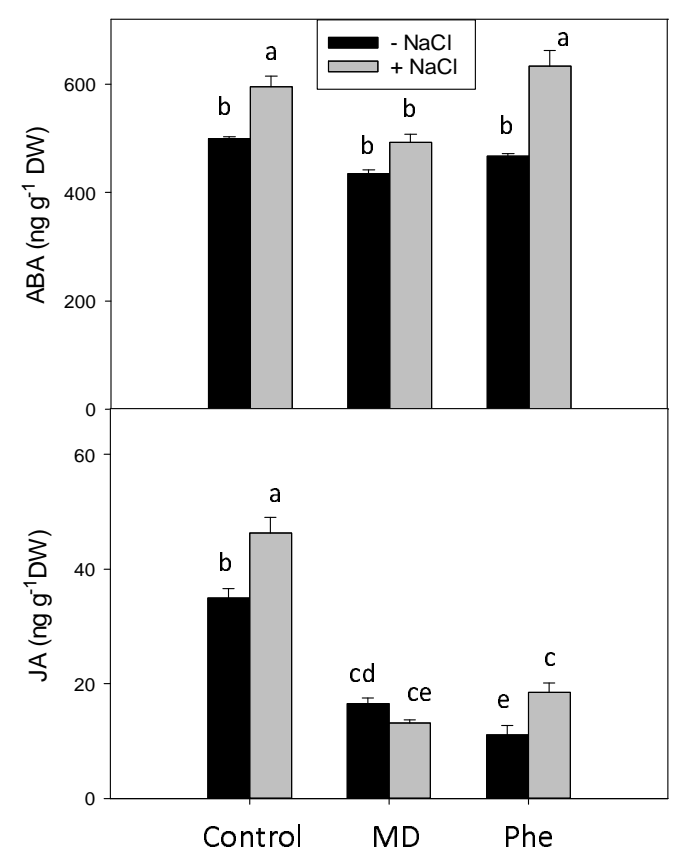

B

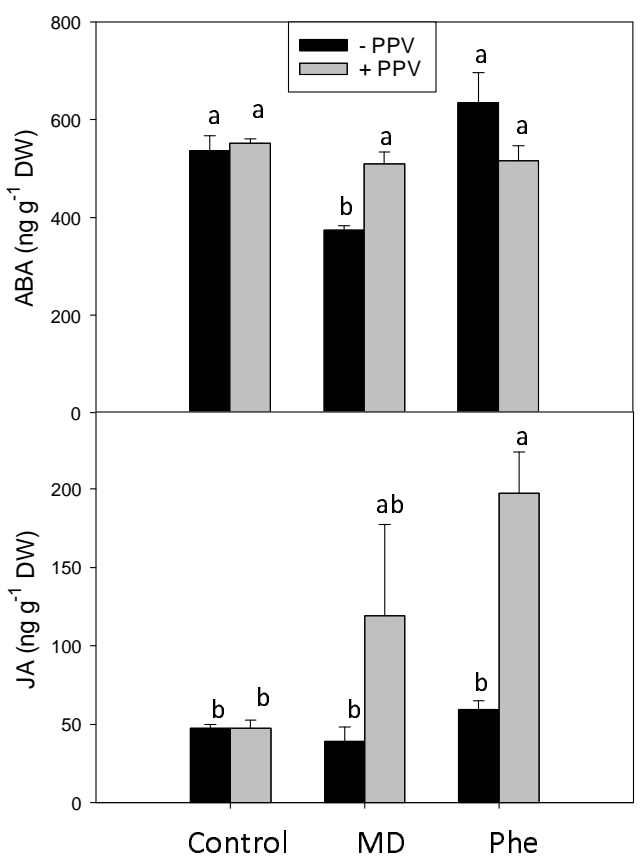

Fig. 6 
A

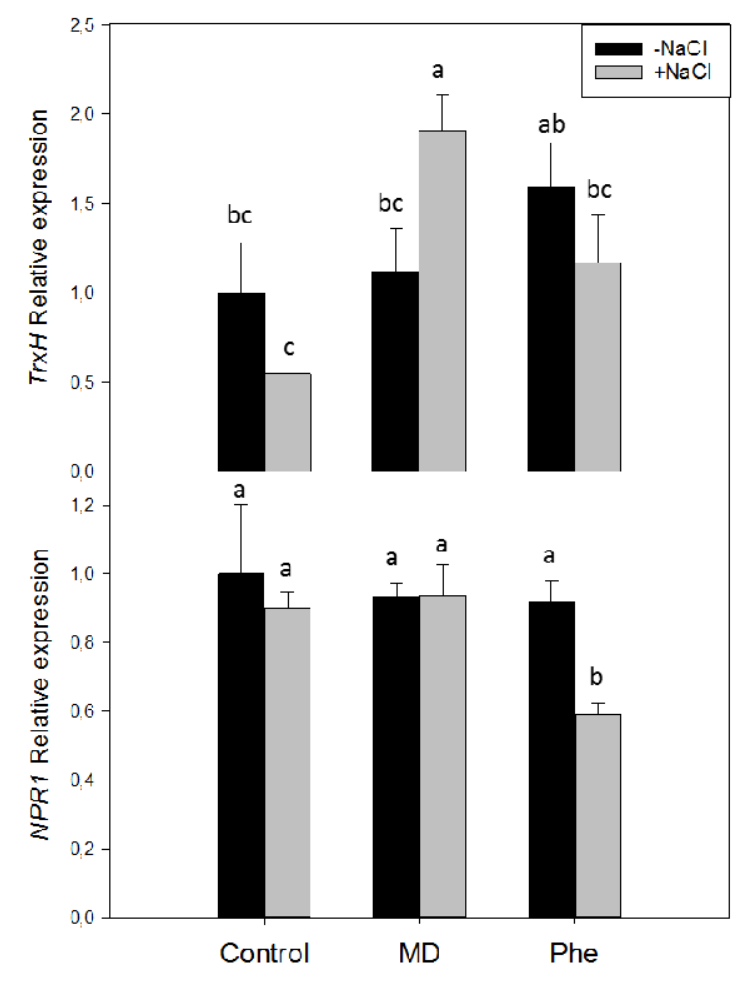

B

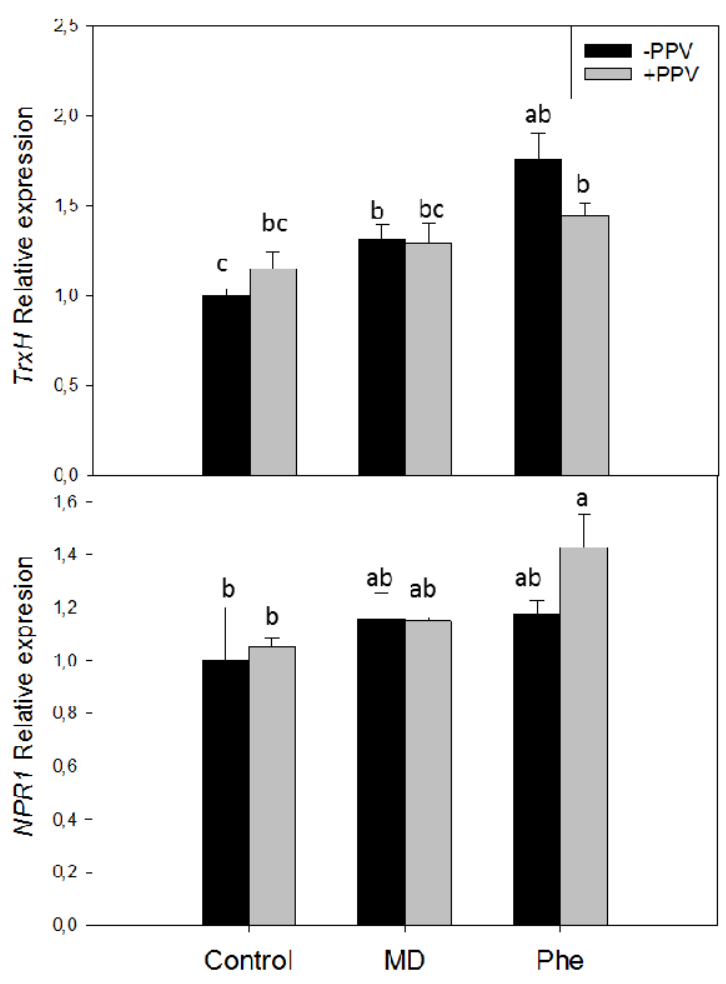

Fìg. 7 